\title{
OPEN Individual dietary specialization reduces intraspecific competition, rather than feeding activity, in black amur bream (Megalobrama terminalis)
}

Yuguo Xia ${ }^{1,2}$, Yuefei $\mathrm{Li}^{1,2}$, Shuli Zhu ${ }^{1,2}$, Jie $\mathrm{Li}^{1,2}$, Shanghao $\mathrm{Li}^{1}$ \& Xinhui $\mathrm{Li}^{1,2 \varpi}$

Individual specialization and high plasticity in feeding activity are common in natural populations. However, the role of these two in intraspecific competition is unclear. In this study, the rhythm of feeding activity, dietary composition, niche width, niche overlap, and individual specialization was explored in four different size groups of black amur bream (Megalobrama terminalis), using microscopic identification of foregut contents and stable isotope analysis $\left(\delta^{13} \mathrm{C}\right.$ and $\left.\delta^{15} \mathrm{~N}\right)$ of dorsal muscle. Both methods observed ontogenetic shifts in dietary preference and individual specializations, and revealed that the total niche width of large individuals was greater than small individuals. Mixed linear models indicated that feeding activity was significantly influenced by time $(p<0.0001)$, and no significant changes among size groups was evident $(p=0.244)$. Niche overlaps revealed that there was intensive diet competition between different size groups of black amur bream. Individual specialization in small juveniles was likely to be stronger than sub-adult and adult groups. Pearson's correlation analysis revealed that the individual specialization was positively correlated with mean diet similarity within a group. The results indicated that intraspecific competition is reduced mainly by individual dietary specialization, rather than shift in feeding activity.

Competitive processes in population ecology influence the spatial and temporal patterns in the members of a population, and how this works has always been a great concern for ecologists ${ }^{1}$. In a given ecosystem, competition refers to the symbiotic interactions between organisms for limited resources, including interspecific and intraspecific competition, and this limits population densities ${ }^{2}$. Intraspecific competition is generally more intense than interspecific competition due to the same requirements for reproduction and growth ${ }^{3}$. Competitions for food, living space, and a mate (or a combination of these) were considered as the main types of intraspecific competition. Food competition could influence fish behavior and offspring survival in the short term, and reduce fish growth and delay maturing in the long term ${ }^{4,5}$. Low abundance of available food resources promotes diversification of fish by size, indicating that body size distribution is affected by competitive interactions ${ }^{6,7}$. Individuals with a similar body size within the same species present more intense competition than those with large size differences ${ }^{1}$. Current data suggest that trophic polymorphism and behavioral differences are important to reduce intraspecific competition in fish species ${ }^{8}$. Behavior patterns in fishes are often said to be plastic. In a laboratory experiment, time of food availability has a great effect on goldfish (Carassius auratus) activity, and different individuals present different activity patterns ${ }^{9}$.

Individual specialization is defined as an individual using a small subset of the population's resource base, and can widely be found in a variety of animals, and even in individuals within a sex and age class ${ }^{10,11}$. Empirical studies have shown that individual specialization is found in many ecological attributes, such as fecundity, resource use, and susceptibility to predation, which is attributed to genetic and environment-based variation ${ }^{12-14}$. Between-individual differences in competition, predation, and pathogen infection risk could be caused by niche divergence ${ }^{15,16}$, thus it is important to understand the strength of individual specializations within species, and

${ }^{1}$ Pearl River Fisheries Research Institute, Chinese Academy of Fishery Sciences, Guangzhou 510380, China. ${ }^{2}$ Experimental Station for Scientific Observation on Fishery Resources and Environment in the Middle and Lower Reaches of the Pearl River, Ministry of Agriculture and Rural Affairs, Zhaoqing 526100, China. ${ }^{\square}$ email: Ixhui01@aliyun.com 


\begin{tabular}{|l|l|l|l|l|}
\hline Group & SL $($ mean \pm SD $)$ & Wt $($ mean \pm SD $)$ & GSI $($ mean \pm SD $)$ & N \\
\hline Small juvenile & $143.6 \pm 17.5^{\mathrm{a}}$ & $66.8 \pm 26.9^{\mathrm{a}}$ & $0.27 \pm 0.31^{\mathrm{a}}$ & 65 \\
\hline Large juvenile & $193.9 \pm 14.6^{\mathrm{b}}$ & $163.2 \pm 43.6^{\mathrm{b}}$ & $0.73 \pm 1.03^{\mathrm{a}}$ & 91 \\
\hline Sub-adult & $241.5 \pm 14.4^{\mathrm{c}}$ & $323.8 \pm 84.8^{\mathrm{c}}$ & $2.06 \pm 2.51^{\mathrm{b}}$ & 96 \\
\hline Adult & $287.3 \pm 18.5^{\mathrm{d}}$ & $566.2 \pm 165.0^{\mathrm{d}}$ & $4.5 \pm 3.51^{\mathrm{c}}$ & 42 \\
\hline
\end{tabular}

Table 1. Basin biological information of different size groups of black amur bream collected in the Pearl River, China. Different superscript letters indicate significant differences (Tukey HSD, $p<0.05$ ). N, sample size, and same as follows.

variations among populations for evaluation of population dynamics. Individual specialization in diet plays a vital role in intraspecific variation, such as intestine length, and jaw structure ${ }^{17}$. Intra- and interspecific competition, diversity of available resources, and predation may modify the strength of individual specialization ${ }^{11}$.

Optimal foraging theory (OFT) hypothesizes that the animal's diet will be such that the net rate of energy intake is maximized, depending on individuals' capacity to capture and digest those resources ${ }^{18}$. OFT explains why dietary differences between individuals of a population occur. Changes in consumer choice occur as the number of competing individuals increases ${ }^{19}$. The range of food items of a species increases as the number of individuals increases within a population, and the extent of individual specialization will also increase ${ }^{20}$. The most competitive or dominant individuals in a population negatively affect the foraging efficiency of weaker conspecifics, that then lose the best foraging areas, and have reduced access to preferred resources ${ }^{21-23}$. This demonstrates that intraspecific competition strengthens individual specialization.

In the present study, the role of feeding rhythm divergence, and individual specialization in reducing intraspecific dietary competition in a freshwater ecosystem was explored. Black amur bream (Megalobrama terminalis) is an economically important, omnivorous species which is abundant in the lower reaches of the Pearl River in China. It has been reported that black amur bream mainly consume golden mussel (Limnoperna fortunei), Asian clam (Corbicula fuminea), organic debris, and aquatic plants ${ }^{24}$. Small subunit ribosomal DNA sequencing analysis revealed that the black amur bream presented dietary shifts during gonad maturation ${ }^{25}$. During the past decade, biomass percentage of black amur bream in catches has decreased by $18.3 \%{ }^{26,27}$, and the stock status of this species is overexploited ${ }^{28}$. Therefore, it is important to assess the implications of population niche, niche overlap, and variation in individual specialization of black amur bream in fish stock decline.

\section{Results}

Gut content composition. A total of 294 black amur bream were collected; the size of specimen ranged from 90 to $345 \mathrm{~mm}$ TL with a mean size $( \pm S D)$ of $212 \pm 50 \mathrm{~mm}$. All samples were divided into four size groups based on standard length and gonadosomatic index. Among them 65 (22\%), 91 (31\%), 96 (33\%), and 42 (14\%) individuals were small juvenile, large juvenile, sub-adult and adult, respectively (Table 1). A total of 28 prey items from 37 intestinal tracts were assigned to taxa. The prey items that were identified to the order level represent over $98 \%(\% \mathrm{~W}$ and $\% \mathrm{~N})$ of all prey examined in each group (Table 2$)$. The percent by weight of gut contents was dominated by detritus across all groups with an average biomass percentage of $>84 \%$. Small juveniles consumed a wider variety of prey that consisted of 20 prey taxa. Besides detritus, the most common prey taxa were Chaetophorales $(5.5 \% \mathrm{~W})$, followed by Coscinodiscales $(0.2 \% \mathrm{~W})$, and Araphidiales $(0.2 \% \mathrm{~W})$. Large juveniles fed on three major prey taxa besides detritus, Mytiloida, Chaetophorales and Ulvales, with biomass percentages of $13.8 \%, 1.4 \%$ and $0.1 \%$, respectively. Sub-adult individuals mainly fed on detritus and Mytiloida, comprising 96.8\% and 3.1\% by weight respectively. Detritus and Mytiloida also dominated the adult diet, comprising $92.7 \%$ and $7.2 \%$ by weight, respectively.

The percent by number of prey taxa in a given individual gut was different to the percent by weight due to the different volumes. The amount of detritus was hard to determine, and we excluded while calculating the percent by number. Four prey taxa, Coscinodiscales, Chaetophorales, Chlorococcales and Aulonoraphidinales dominated the small juvenile diet, cumulatively comprising $87.1 \%$ by number (Table 2 ). The prey taxa, Chaetophorales, dominated the large juvenile diet, comprising $43.4 \%$ by number. Sub-adults mainly fed on Coscinodiscales comprising $45.0 \%$ by number, and Aulonoraphidinales and Mytiloida were also recorded in rare instances (Table 2). The most abundant prey taxon was Coscinodiscales $(50.2 \% \mathrm{~N})$ in the adult group, and Araphidiales, Biraphidinales, Aulonoraphidinales, and Mytiloida were also found in some adult individuals.

Overall, the gut content compositions of the different size groups did not vary greatly, as indicated by small variations for the major prey taxon detritus in percent by weight (Table 2). However, the prey taxa varied greatly between size groups in percent number. Black amur bream demonstrated different diet preferences in relation to body length.

Feeding activity. During the sampling period of $24 \mathrm{~h}$, the black amur bream was considered to be actively feeding at all times (Fig. 1). The highest fullness index (FI) of small juvenile was observed around 16:00, and the lowest around 13:00. After sunset, before mid-night (19:00-22:00), the gut fullness stayed at an intermediate level. From 1:00 to 10:00, the gut fullness was at a low level. The large juveniles generally had a greater fullness than small juveniles, and feeding activity did not vary across all times. The highest gut fullness in sub-adults was observed around 1:00, and sharply decreased by 4:00, and continued to decline until 7:00. During the late morn- 


\begin{tabular}{|l|l|l|l|l|}
\hline Food item & $\begin{array}{l}\text { Small juvenile } \\
(\mathbf{N}=9)\end{array}$ & $\begin{array}{l}\text { Large juvenile } \\
(\mathbf{N}=\mathbf{6})\end{array}$ & $\begin{array}{l}\text { Sub-adult } \\
(\mathbf{N}=\mathbf{1 5})\end{array}$ & $\begin{array}{l}\text { Adult } \\
(\mathbf{N}=7)\end{array}$ \\
\hline Percent by weight \% (\%W, mean \pm SD) \\
\hline Detritus & $94.1 \pm 16.4$ & $84.5 \pm 33.3$ & $96.8 \pm 7.0$ & $92.7 \pm 14.8$ \\
\hline Chaetophorales & $5.5 \pm 16.4$ & $1.4 \pm 3.0$ & 0 & 0 \\
\hline Mytiloida & 0 & $13.8 \pm 33.9$ & $3.1 \pm 7.1$ & $7.2 \pm 14.9$ \\
\hline Coscinodiscales & $0.2 \pm 0.2$ & $0.02 \pm 0.04$ & $0.08 \pm 0.15$ & $0.05 \pm 0.08$ \\
\hline Araphidiales & $0.2 \pm 0.5$ & $0.05 \pm 0.12$ & $0.04 \pm 0.08$ & $0.01 \pm 0.01$ \\
\hline Ulvales & 0 & $0.1 \pm 0.3$ & 0 & 0 \\
\hline Percent by number \% $(\% \mathbf{N}, \mathbf{m e a n} \pm$ SD) & & & \\
\hline Coscinodiscales & $53.6 \pm 39.3$ & $9.4 \pm 22.6$ & $45.0 \pm 32.6$ & $50.2 \pm 36.7$ \\
\hline Chaetophorales & $12.5 \pm 35.3$ & $43.4 \pm 49.1$ & 0 & 0 \\
\hline Chlorococcales & $11.7 \pm 26.0$ & $0.1 \pm 0.3$ & $16.0 \pm 29.7$ & $14.4 \pm 21.1$ \\
\hline Mytiloida & 0 & $16.7 \pm 40.8$ & $0.02 \pm 0.03$ & $0.02 \pm 0.04$ \\
\hline Araphidiales & $5.9 \pm 12.6$ & $2.4 \pm 5.8$ & $11.7 \pm 11.2$ & $6.7 \pm 7.9$ \\
\hline Chroococcales & $0.1 \pm 0.3$ & 0 & 0 & $26.2 \pm 38.7$ \\
\hline Osillatoriales & $1.0 \pm 2.9$ & 0 & $9.9 \pm 17.5$ & 0 \\
\hline Ulvales & 0 & $6.1 \pm 13.5$ & 0 & 0 \\
\hline Biraphidinales & $4.4 \pm 6.5$ & $21.8 \pm 36.0$ & $15.5 \pm 30.3$ & $1.1 \pm 1.7$ \\
\hline Aulonoraphidinales & $9.3 \pm 20.5$ & 0 & $0.5 \pm 1.5$ & $0.4 \pm 0.6$ \\
\hline
\end{tabular}

Table 2. Identifiable black amur bream prey in each size group sorted by taxa. Items with a percentage by weight over $0.1 \%$ and percentage by number over $1 \%$ are listed. Percentage by number excludes detritus.

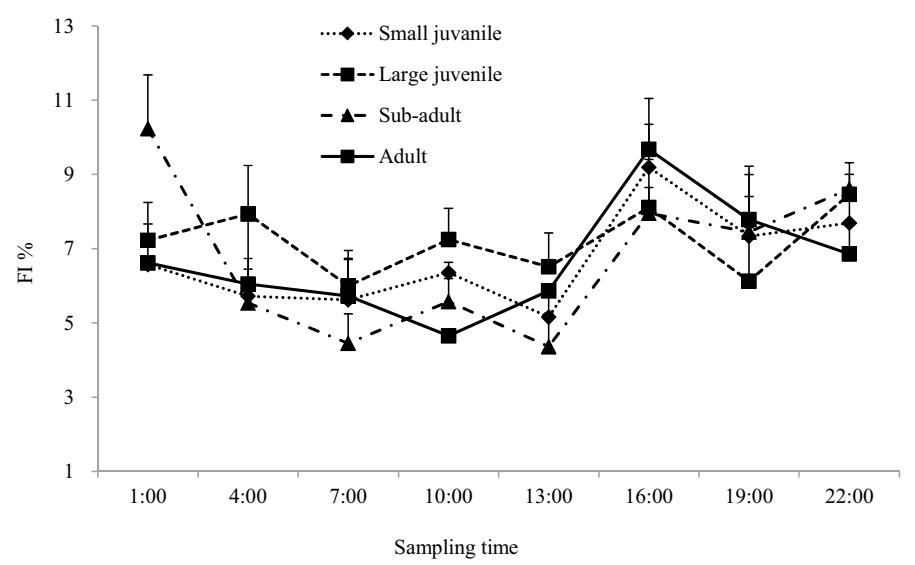

Figure 1. Variation in the gut fullness index $(\% \mathrm{FI}$, mean $\pm \mathrm{SE})$ for the four size groups of black amur bream analyzed during a $24 \mathrm{~h}$ sampling period. This figure created using EXCEL version 2010.

ing, (7:00-13:00), gut fullness was observed to be low. From 16:00 to 22:00, the gut fullness slightly increased and stayed at a medium level. Mean gut fullness of adult individuals was low during the early morning (1:00-7:00), and declined to a minimum at 10:00. During the afternoon, the gut fullness greatly increased and peaked at 16:00, followed by slight decline after sunset (19:00-22:00).

The FF was the response of the mixed linear model; size group, sampling time and the interaction of these two factors were fixed effects; sampling season was the random effect. The results of the ANOVA tested models indicated that sampling time $\left(\chi^{2}=21.432, p<0.0001\right)$ was a significant influence on the feeding activity. The size group did not significantly affect the fish feeding activity $\left(\chi^{2}=1.358, p=0.244\right)$. This demonstrated that there was no significant change in feeding rhythm among individuals.

Trophic niche widths. A total of 46 samples of four size groups of black amur bream and 40 samples of potential prey sources were analyzed for $\delta^{13} \mathrm{C}$ and $\delta^{15} \mathrm{~N}$. There was a high degree of isotope overlap in $\delta^{13} \mathrm{C}$ and $\delta^{15} \mathrm{~N}$ between the size groups (Table 3). The values for black amur bream ranged from -28.44 to $-22.08 \%$ for $\delta^{13} \mathrm{C}$ and from 7.23 to $21.76 \%$ for $\delta^{15} \mathrm{~N}$. Curve estimation indicated that the $\delta^{15} \mathrm{~N}$ value of the black amur bream is a linear function of standard length. All coefficients were statistically significant, and the R-squared value was approximately 0.133 (Fig. $2 \mathrm{~B}, \delta^{15} \mathrm{~N}=8.90+0.02 \times \mathrm{SL}, p=0.013$ ). The $\delta^{13} \mathrm{C}$ value was negatively correlated (linearly) with fish standard length, but the relationship was not significant $(p=0.134$, Fig. $2 \mathrm{~A})$. The $\delta^{13} \mathrm{C}$ and 


\begin{tabular}{|l|l|l|l|l|l|}
\hline Group/taxon & Code & $\mathbf{N}$ & $\boldsymbol{\delta}^{13} \mathbf{C}(\%)$ & $\boldsymbol{\delta}^{15} \mathbf{N}(\%)$ & $\mathbf{C} / \mathbf{N}$ \\
\hline Small juvenile & Small juvenile & 11 & $-24.67 \pm 1.75$ & $11.60 \pm 2.75$ & - \\
\hline Large juvenile & Large juvenile & 12 & $-25.53 \pm 1.43$ & $12.54 \pm 2.44$ & - \\
\hline Sub-adult & Sub-adult & 15 & $-26.10 \pm 1.52$ & $13.53 \pm 2.69$ & - \\
\hline Adult & Adult & 8 & $-25.58 \pm 1.33$ & $14.57 \pm 3.09$ & - \\
\hline Zooplankton & Zooplankton & 2 & $-30.25 \pm 1.07$ & $9.95 \pm 2.08$ & $6.11 \pm 0.66$ \\
\hline Phytoplankton & Phytoplankton & 2 & $-27.94 \pm 0.24$ & $8.21 \pm 1.13$ & $8.40 \pm 1.86$ \\
\hline Riparian C 4 plants & C $_{4-}$ P & 4 & $-13.29 \pm 0.21$ & $4.06 \pm 1.44$ & $63.89 \pm 10.35$ \\
\hline Potamogeton sp. & Psp & 6 & $-25.29 \pm 3.26$ & $7.45 \pm 2.43$ & $10.46 \pm 1.26$ \\
\hline Macrobrachium nipponense & Mni & 9 & $-26.97 \pm 0.66$ & $15.95 \pm 1.32$ & $3.30 \pm 0.07$ \\
\hline Anodonta woodiana & Awo & 2 & $-24.72 \pm 0.65$ & $6.46 \pm 0.04$ & $3.84 \pm 0.06$ \\
\hline Limnoperna fortunei & Lfo & 1 & -26.53 & 4.96 & 4.65 \\
\hline Semisulcospira cancellata & Sca & 1 & -24.16 & 9.51 & 3.91 \\
\hline Corbicula fluminea & Cfl & 4 & $-30.27 \pm 0.26$ & $11.99 \pm 0.31$ & $4.65 \pm 0.43$ \\
\hline Bellamya sp. & Bsp & 4 & $-22.28 \pm 0.34$ & $4.42 \pm 1.02$ & $4.14 \pm 0.27$ \\
\hline Benthic detritus & Bde & 2 & $-26.11 \pm 1.20$ & $7.08 \pm 1.50$ & $12.57 \pm 4.50$ \\
\hline Sediment & Sediment & 3 & $-25.23 \pm 0.39$ & $5.85 \pm 0.23$ & $10.47 \pm 1.23$ \\
\hline
\end{tabular}

Table 3. Summary statistics (mean $\pm \mathrm{SE}$ ) of $\delta^{13} \mathrm{C}, \delta^{15} \mathrm{~N}$, and $\mathrm{C} / \mathrm{N}$ in the different size groups of black amur bream and potential prey sources in the sampling site. Values are mean $\pm \mathrm{SD}$.

$\delta^{15} \mathrm{~N}$ of potential prey taxa ranged from -31.00 to $-13.07 \%$, and from 2.87 to $17.35 \%$, respectively. Riparian $\mathrm{C}_{4}$ plants had the highest $\delta^{13} \mathrm{C}$ and lowest $\delta^{15} \mathrm{~N}$ values, with mean values of $-13.29 \pm 0.21 \%$ and $4.06 \pm 1.44 \%$, respectively. The lowest $\delta^{13} \mathrm{C}$ and highest $\delta^{15} \mathrm{~N}$ values were distributed in Corbicula fluminea and Macrobrachium nipponense, respectively. The other prey taxa had a wider variety of $\delta^{13} \mathrm{C}$ and $\delta^{15} \mathrm{~N}$ values, but overlapped with each other to some extent. The mean values and standard deviations for each fish group and prey taxon for $\delta^{13} \mathrm{C}$ and $\delta^{15} \mathrm{~N}$ are shown in Table 3. The C/N ratio (\% weight) in potential prey taxa ranged from 3.17 to 77.32 , where $M$. nipponense had the minimum value, and riparian $\mathrm{C}_{4}$ plants had the maximum value.

The mean proportional contribution of potential prey sources to black amur bream varied among taxa, observing a range from 0.02 to 0.15 (Table 4). The contribution of 12 potential taxa to small juveniles ranged from 0.05 to 0.10 , with $C$. fluminea in the highest proportion, and $\mathrm{C}_{4-} \mathrm{P}$ in the lowest proportion. The mean contributions of other prey to small juveniles were almost similar. The riparian C4 plant contributions were always low across all size groups. The mean proportional contributions of zooplankton, $M$. nipponense and C. fluminea were high, demonstrated to be very important for black amur bream. The contributions of M. nipponense and C. fluminea increased from small to adult individuals, and contributions of prey sources within groups also increased with body length. This appeared to be a dietary shift during fish growth.

The total trophic niche width was assessed using both gut contents and stable isotopes through TNW and $\mathrm{SEA}_{c}$, respectively. The higher values indicated a greater niche width in a given group. Both methods showed consistent results, with the trophic niche width increasing with body length. The values of the TNW and SEA varied among size groups: adult $>$ sub-adult $>$ large juvenile $>$ small juvenile (Table 5).

Niche overlap. The pairwise Morisita's dietary overlap index was generally $>0.6$ between any two size groups, and very close to 1 . Both carbon and nitrogen isotopic values exhibited no significant difference between the four size groups (ANOVA, $p=0.156$ and 0.104 for $\delta{ }^{13} \mathrm{C}$ and $\delta{ }^{15} \mathrm{~N}$ respectively). These similarities suggested niche partitioning among the four size groups, with large $\mathrm{SEA}_{c}$ overlap (Fig. 3). The $\mathrm{SEA}_{c}$ of four size groups overlapped with each other on the isotope biplot, with the largest overlap area occurring between sub-adult and adult, whereas the smallest overlap occurred between small juveniles and adult (Table 6). Both methods (Morisita's index and $\mathrm{SEA}_{c}$ overlapping) indicated a high potential for resource competition within the population of black amur bream.

Individual specialization. Individual prey specialization was assessed using both gut contents and stable isotopes through the WIC/TNW $\mathrm{g}$ and CD, respectively. Low WIC/TNW $\mathrm{g}$ and high CD both indicated less similarity between individuals. Both methods provided higher individual specialization in small juveniles than in sub- and adult groups. Pearson's correlation analysis revealed that mean pairwise diet similarity was negatively

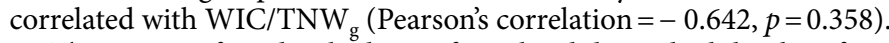

The NR was found to be larger for sub-adults and adults than for juvenile groups, whereas CR was high in the sub-adult group, and low in the adult group (Table 5). A slightly higher mean trophic diversity (assessed by CD) was found in small juveniles compared with other size groups. The RPP test indicated that the CD in the small juveniles did differ significantly from the sub-adult $(p=0.026)$ and adult $(p=0.019)$ groups. The MNND did not differ significantly between size groups $(p>0.05)$. The Hotelling's $T^{2}$ tests revealed that centroid location did not differed significantly (Euclidean distance between centroids was not significantly different from zero) for the contrast of the small juveniles and adults (Hotelling's $T^{2}=5.81, p=0.089$ ). 


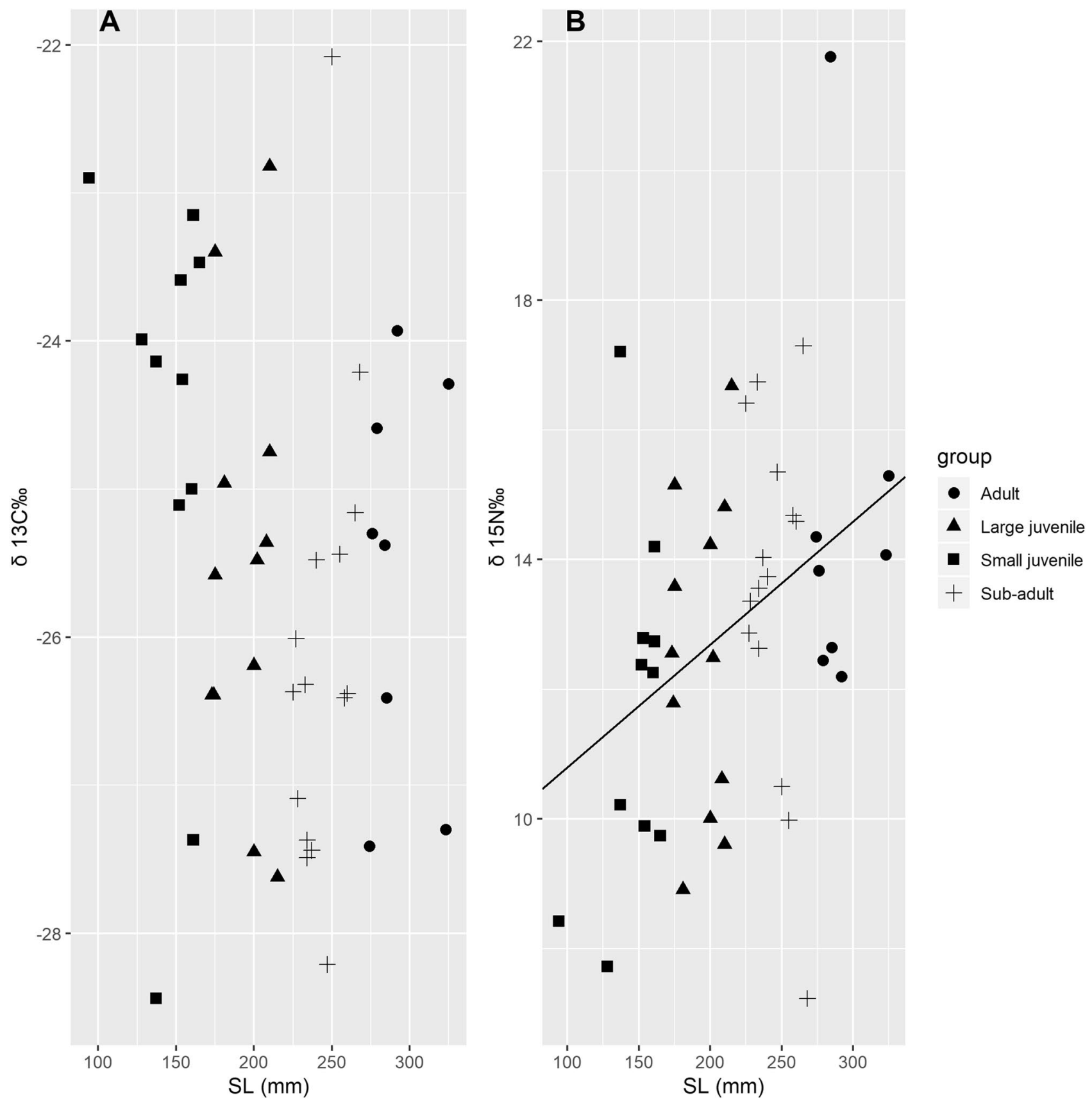

Figure 2. The relationship between isotope values and standard length of black amur bream. This figure created using R software version 3.6.1 (https://www.r-project.org/).

\section{Discussion}

Although black amur bream have been an economically important species in the Pearl River basin for many decades, only a handful of studies have explored their feeding ecology ${ }^{24,25}$. The goal of the present study was to improve the understanding of intraspecific dietary competition, and its influencing factors, which is important to the protection and sustainable use of black amur bream. Gut contents and stable isotope analyses were both used to compare feeding rhythm, niche overlap, and individual specialization among four size groups.

Prey composition different revealed by gut content and stable isotope. Remains of prey in the foregut samples were difficult to identify by microscopic observation due to digestion. The proportions of prey items in black amur bream were very different by weight or by number. Dietary preference shifts were observed during fish growth, where juveniles preferred to consume phytoplankton and adult consumed more animal material. Dietary shift is common in fish and are closely related to the ontogenetic changes in energy demands, and foraging performance ${ }^{29,30}$. Dietary composition of the black amur bream is supported by a previous study in the Pearl River with a high consumption of detritus ${ }^{24}$. Small subunit ribosomal DNA (18S rDNA) sequenc- 


\begin{tabular}{|l|l|l|l|l|l|l|l|l|}
\hline \multirow{2}{*}{ Prey } & \multicolumn{2}{l}{ Small juvenile } & \multicolumn{2}{l|}{ Large juvenile } & \multicolumn{2}{l|}{ Sub-adult } & \multicolumn{2}{l|}{ Adult } \\
\cline { 2 - 10 } & Mean & CI95\% & Mean & CI95\% & Mean & CI95\% & Mean & CI95\% \\
\hline Zooplankton & 0.09 & $0-0.18$ & 0.11 & $0-0.21$ & 0.13 & $0-0.25$ & 0.11 & $0-0.21$ \\
\hline Phytoplankton & 0.08 & $0-0.17$ & 0.09 & $0-0.19$ & 0.09 & $0-0.20$ & 0.09 & $0-0.19$ \\
\hline C__P $_{\text {Psp }}$ & 0.05 & $0-0.11$ & 0.03 & $0-0.07$ & 0.02 & $0-0.06$ & 0.03 & $0-0.08$ \\
\hline Pni & 0.09 & $0-0.17$ & 0.08 & $0.01-0.18$ & 0.07 & $0-0.18$ & 0.08 & $0-0.19$ \\
\hline Awo & 0.09 & $0-0.17$ & 0.11 & $0-0.20$ & 0.14 & $0.03-0.25$ & 0.15 & $0.02-0.27$ \\
\hline Lfo & 0.08 & $0-0.17$ & 0.07 & $0-0.17$ & 0.05 & $0-0.14$ & 0.06 & $0-0.15$ \\
\hline Sca & 0.09 & $0-0.17$ & 0.08 & $0-0.17$ & 0.06 & $0-0.15$ & 0.06 & $0-0.16$ \\
\hline Cfl & 0.08 & $0-0.17$ & 0.07 & $0-0.17$ & 0.06 & $0-0.15$ & 0.07 & $0-0.16$ \\
\hline Bsp & 0.10 & $0-0.18$ & 0.13 & $0.01-0.23$ & 0.15 & $0.01-0.29$ & 0.12 & $0.01-0.23$ \\
\hline Bde & 0.08 & $0-0.16$ & 0.06 & $0-0.14$ & 0.04 & $0-0.10$ & 0.05 & $0-0.13$ \\
\hline Sediment & 0.08 & $0-0.17$ & 0.08 & $0-0.18$ & 0.09 & $0-0.20$ & 0.09 & $0-0.19$ \\
\hline
\end{tabular}

Table 4. Contributions of different potential prey taxa to different size groups of black amur bream, according to stable isotope Bayesian mixed models. CI95\%, lower-higher confidence intervals.

\begin{tabular}{|l|l|l|l|l|}
\hline & Small juvenile & Large juvenile & Sub-adult & Adult \\
\hline Taxonomic richness per gut $($ mean \pm SD) & $5.5 \pm 3.0^{\mathrm{a}}$ & $2.8 \pm 1.5^{\mathrm{a}}$ & $4.8 \pm 2.2^{\mathrm{a}}$ & $4.8 \pm 1.6^{\mathrm{a}}$ \\
\hline TNW & 0.058 & 0.699 & 0.862 & 0.938 \\
\hline WIC/TNW & 0.250 & 0.951 & 0.637 & 0.610 \\
\hline Diet similarity & 0.339 & 0.185 & 0.375 & 0.386 \\
\hline NR $(\%)$ & 9.49 & 7.77 & 10.07 & 9.56 \\
\hline CR $(\%)$ & 5.54 & 4.80 & 6.13 & 3.48 \\
\hline CD $(\%)$ & 2.61 & 2.40 & 2.47 & 2.55 \\
\hline MNND \pm SD(\%) & $1.04 \pm 1.07$ & $1.37 \pm 0.62$ & $1.15 \pm 1.10$ & $1.69 \pm 2.05$ \\
\hline TA & 19.22 & 21.74 & 30.87 & 17.52 \\
\hline SEA (\%) & 9.446 & 10.041 & 11.240 & 12.957 \\
\hline SEA $(\%)$ & 10.496 & 11.045 & 12.104 & 15.116 \\
\hline
\end{tabular}

Table 5. Metrics quantifying trophic niche and individual specialization in black amur bream. Same superscript letters indicate no significant differences (Kruskal-Wallis test, $p>0.05$ ).

ing also detected juvenile black amur bream with highly abundant Streptophyta, and adults with more benthic animals $^{25}$. The $18 \mathrm{~S}$ rDNA sequencing method identified prey items along with intestinal microbes, while gut content identification can more accurately determine the contribution of each item. However, microscopic evaluation of foregut contents overestimated detritus, but this did not great affect the calculation of dietary overlap due to the high percentage of detritus in each size group.

Stable isotope analysis provides a powerful tool to characterize carbon sources and trophic position ${ }^{31}$, but is biased to detecting specific trophic interactions as isotope values in potential prey often overlap ${ }^{32}$. The stable isotope analysis showed that almost all prey taxa contribute to black amur bream nutrition (Table 4), which may be attributed to the trophic interactions among prey items. However, isotope analysis revealed the variation in the contribution of given prey items to the four size groups with results concurring with gut content analysis. The number of prey items determined by isotope analysis was much less than visual, and molecular identification of gut contents ${ }^{25}$. Two isotope ratios powerful evaluated the flow of organic material from three prey items to consumers ${ }^{33}$, but it is hard to determine more than three preys due to the variation in trophic fractionations between preys and consumers ${ }^{34-36}$.

High intraspecific dietary competition of black amur bream. In addition to the shift in dietary preference, there is an increase in the niche width of black amur bream during fish growth. Competing theories assumed that ecosystem productivity increases the niche width of omnivores, which decreases as consumers utilize distinctive prey items $s^{37,38}$. Trophic niche width is also closely related to the intensity of competition, which tended to increase under some environmental conditions ${ }^{39}$. Large individuals are generally superior to small sized individuals when competing for food, with a higher growth rate and wider dietary sources ${ }^{40}$. The niche width of adult black amur bream was larger than juvenile individuals may mainly due to ontogenetic changes in feeding ability.

Both methods visual identification and isotope analysis consistently revealed high intraspecific dietary competition in black amur bream. It has been reported that the primary production of phytoplankton in the mainstream of the Pearl River is less than $400 \mathrm{mg}\left(\mathrm{m}^{2} \mathrm{~d}\right)^{-1}$, and biomass of riparian and submersed plants is very low ${ }^{41,42}$. Low 


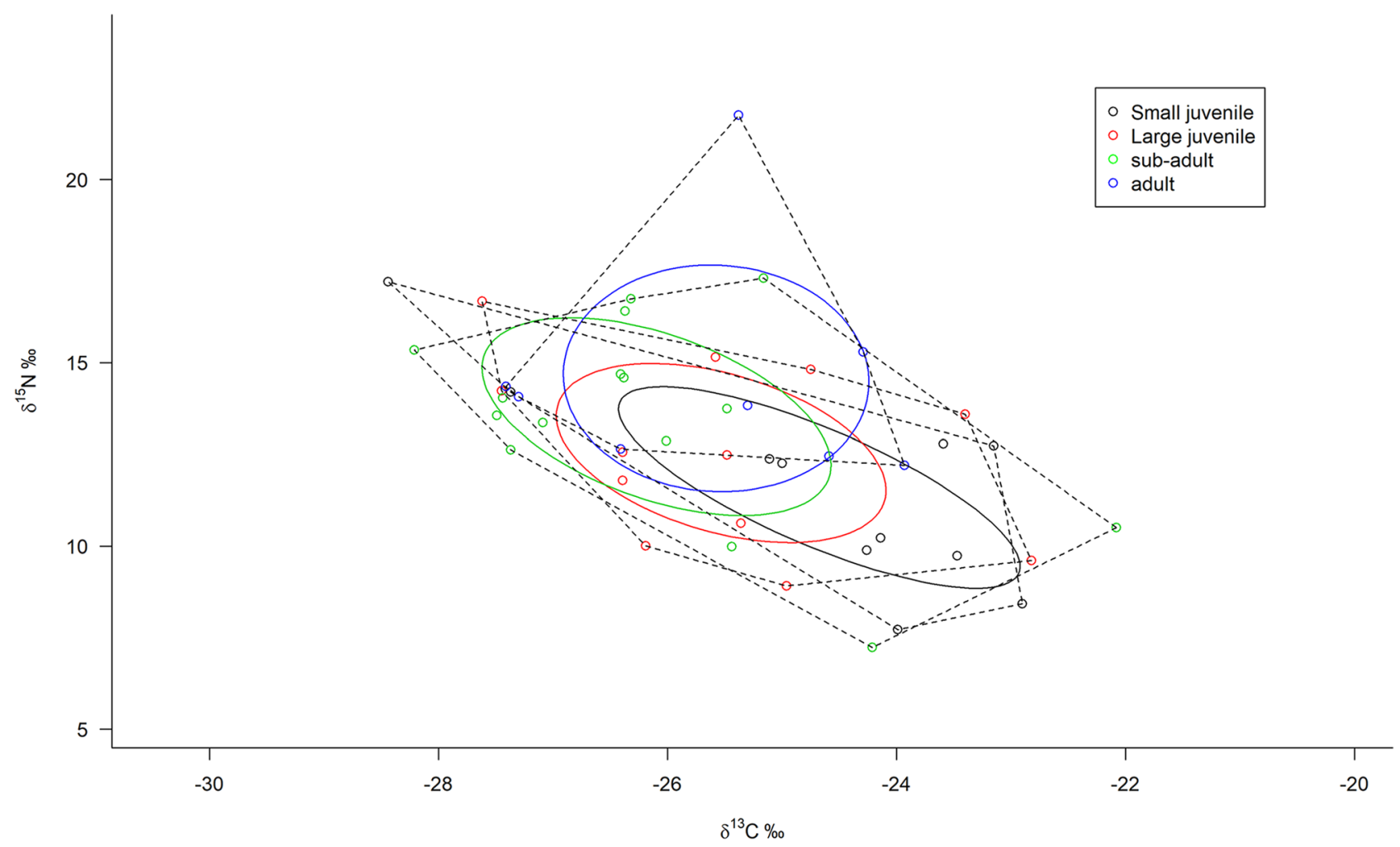

Figure 3. The area of convex hulls (TA) of $\delta^{13} \mathrm{C}$ and $\delta^{15} \mathrm{~N}$ values plotted by dashed lines according to the four size groups of black amur bream. The area of standard ellipse $\left(\mathrm{SEA}_{c}\right)$ is drawn by solid line, and contains $40 \%$ of the data. This figure created using R software version 3.6.1 (https://www.r-project.org/).

\begin{tabular}{|c|c|c|c|}
\hline & Small juvenile & Large juvenile & Sub-adult \\
\hline \multicolumn{4}{|c|}{ Morisita's dietary overlap index } \\
\hline Large juvenile & 0.982 & & \\
\hline Sub-adult & 0.997 & 0.984 & \\
\hline Adult & 0.995 & 0.993 & 0.998 \\
\hline \multicolumn{4}{|c|}{$\mathrm{SEA}_{c}$ overlap $\left(\%^{2}\right)$ between groups (percentage in parentheses) } \\
\hline Large juvenile & $45.96(0.52)$ & & \\
\hline Sub-adult & $46.62(0.48)$ & $51.29(0.59)$ & \\
\hline Adult & $44.23(0.39)$ & $51.81(0.51)$ & $54.18(0.53)$ \\
\hline
\end{tabular}

Table 6. Pairwise trophic overlap using Morisita's index and geometric overlap area of corrected standard ellipse area $\left(\mathrm{SEA}_{c}\right)$ among four size groups of black amur bream.

abundance of available prey resources could be the reason for high intraspecific competition, and busy feeding activities occurring during the $24 \mathrm{~h}$ sampling period seem to prove this hypothesis (Fig. 1). The proportion of starving black amur bream $(\mathrm{FF}=0$ or 1$)$ was about $11 \%$ by number.

Individual specialization reduces intraspecific dietary competition. Variation among individuals within populations is an evidence of competition, and has important consequences for ecological interactions ${ }^{13}$. Natural selection holds that competition intensity should decline over time among sympatric populations due to adaptive change, facilitating natural population persistence ${ }^{43,44}$. Generally, high individual specialization represents populations that possess considerable diversity and great variation, promoting resource portioning and coexistence. The highest individual specialization was found in small juvenile black amur bream (lowest WIC/ TNW), which may be explained by the high individual variation cause by limited foraging abilities within this group. Diet similarity between individuals in a group was negatively correlated with WIC/TNW, which demonstrated that intraspecific diet competition was positively correlated with individual specialization. On average, the WIC/TNW value was $0.66 \pm 0.21$ ( $\mathrm{n}=78$ populations), and individuals' niches were narrower than population niches ${ }^{11}$. The value of WIC/TNW $\mathrm{g}$ in small juvenile black amur bream was much less than the average level, indicating high intraspecific competition. Low foraging efficiency and high conspecific densities may contribute 
to high competition in the small juvenile group ${ }^{45,46}$. Low variation among individuals in sub-adults and adult may be due to exploitation competition, where one individual depletes a food patch before another one arrives ${ }^{4}$. An extremely high value of $\mathrm{WIC} / \mathrm{TNW}_{\mathrm{g}}$ was found in the large juvenile group (Table 5), probably because of the low prey taxonomic richness, which may underestimate the dietary variations among individuals within this

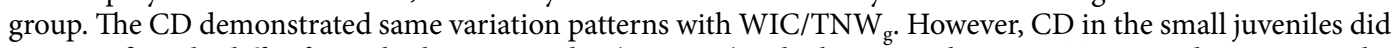
not significantly differ from the large juveniles $(p=0.330)$, which proves that WIC/TNW underestimates the dietary variations in the large juvenile group.

\section{Conclusions}

Ontogenetic changes in dietary preference and plasticity in feeding activity are common in fish; however, the role of these two in intraspecific competition is unclear. The results showed that juvenile black amur bream preferred to consume phytoplankton and adult consumed more animal material. However, there were no ontogenetic changes in rhythms of feeding activity of black amur bream. Although dietary shift was found in black amur bream, there was great dietary overlap and intense competition between different sized individuals. Moreover, diet similarity within a size group was positively correlated with individual specialization. The results indicated that intraspecific diet competition was reduced by individual specialization, rather than divergence in feeding activity. The challenge for the future is to understand the contribution of genetic variance and morphological feeding differences to individual specialization, and how the strength of individual specialization changes with ecological interactions.

\section{Materials and methods}

Sample collection and preparation. The Pearl River is the longest river in southern China, with a total length and annual discharge of $2214 \mathrm{~km}$ and $10,000 \mathrm{~m}^{3} \mathrm{~s}^{-1}$, respectively. The present study was conducted in the Zhaoqing section $\left(23^{\circ} 02^{\prime}-04^{\prime} \mathrm{N}, 112^{\circ} 25^{\prime}-31^{\prime} \mathrm{E}\right)$ in the lower reaches of the Pearl River. Fish samples were collected in the dry season of 2015-2017, and the flood season of 2017 and 2019. Sampling was carried out with circular cast nets $(15 \mathrm{~m}$ diameter, mesh size $4 \mathrm{~cm}$ ). Eight daily hauls of $1 \mathrm{~h}$ each were performed every $3 \mathrm{~h}$ throughout a $24 \mathrm{~h}$ period to cover the entire diel cycle. The samples, kept on ice immediately and subsequently refrigerated, were transported to the laboratory. Each fish was measured for standard length (SL) to the nearest $1 \mathrm{~mm}$, weighed for body weight $\left(\mathrm{W}_{\mathrm{t}}\right)$, gonad weight $\left(\mathrm{W}_{\mathrm{g}}\right)$ and gut weight $\left(\mathrm{W}_{\text {gut }}\right)$ to the nearest $0.1 \mathrm{~g}$, and sex and maturity stage was recorded. The foregut was removed, and the contents were weighed to the nearest $0.0001 \mathrm{~g}$. A sample of dorsal muscle was dissected and stored at $-20^{\circ} \mathrm{C}$ for stable isotope analysis. Gonadosomatic index (GSI) and fullness index (FI) were calculated by the biomass percentage of gonad and gut to body mass, respectively. The GSI and FI were defined as follows:

$$
\begin{aligned}
& \text { GSI }=100 \times \mathrm{W}_{\mathrm{g}} / \mathrm{W}_{\mathrm{t}}, \\
& \mathrm{FI}=100 \times \mathrm{W}_{\text {gut }} / \mathrm{W}_{\mathrm{t}} .
\end{aligned}
$$

Potential prey sources including phytoplankton, zooplankton, invertebrate, riparian $\mathrm{C}_{4}$ plants, submersed plants, benthic detritus and sediment were collected in the dry season of 2017 and 2018. Phytoplankton was collected by a horizontally hauled phytoplankton net $(25 \#, 64 \mu \mathrm{m})$ from $0.5 \mathrm{~m}$ below the surface, and repeated until enough sample was collected. The phytoplankton samples were suspended in distilled water for at least $2 \mathrm{~h}$, and then passed through plankton net $(13 \#, 112 \mu \mathrm{m})$ to remove zooplankton and large particles. The phytoplankton was filtered onto pre-combusted Whatman GF/F glass fiber filters $\left(0.7 \mu \mathrm{m}, 450^{\circ} \mathrm{C}\right.$ for $\left.8 \mathrm{~h}\right)$. Zooplankton samples were collected using the plankton net (13\#), with the same preparation method as phytoplankton.

Benthic macroinvertebrates were collected with a weighted Petersen grab $\left(1 / 16 \mathrm{~m}^{2}\right)$, and the samples were sieved through a $420 \mu \mathrm{m}$ sieve $\mathrm{e}^{47}$. In the laboratory, benthic animals were picked and kept in distilled water for $12 \mathrm{~h}$ to empty their gut contents. The benthic detritus was collected from the residue after the benthic animals were removed. Sediment samples were collected using Petersen grab, benthic animals were removed, and the sample was divided into two parts at each sampling site. One part was acidified with hydrochloric acid vapor in an enclosed space for $24 \mathrm{~h}$ to remove any carbonate for carbon isotope analysis, and the other part used for nitrogen isotope analysis. Plants were collected by hand, and then rinsed in distilled water. Riparian $\mathrm{C}_{4}$ plants were dominated by Hemarthria altissima and Cynodon dactylon, and submersed plants included Potamogeton crispus and P. pectinatus. Several individuals (5-20) of small species like Corbicula fluminea and Limnoperna fortune were pooled to make a single sample of adequate sample mass. The preparation of macroinvertebrates was as previously described ${ }^{48}$.

All samples for stable isotope analyses were freeze-dried at $<40 \mathrm{~Pa}$ and $<-40^{\circ} \mathrm{C}$ for $48 \mathrm{~h}$ (FD-1-50 Plus, $\mathrm{BIOCOOL}$ ) and then ground into a fine powder using an automated vibration ball grinder (except for the filtered samples). The stable isotopes $\delta^{13} \mathrm{C}$ and $\delta^{15} \mathrm{~N}$ were measured using a Thermo DELTA V Advantage Isotope Ratio Mass Spectrometer with external Flash EA1112 HT Elemental Analyzer equipment. Stable isotope ratios were expressed as parts per thousand (\%o) of the international standards. The Vienna Pee Dee Belemnite and atmospheric nitrogen were used as the standards for carbon and nitrogen, respectively. Analytic precision was $\pm 0.1 \%$ for $\delta^{13} \mathrm{C}$ and $\pm 0.2 \%$ for $\delta^{15} \mathrm{~N}$, respectively. The $\mathrm{C} \%$ or $\mathrm{N} \%$ of each sample was calculated using the relative peak area of the sample to a working standard.

Feeding activity. Fish fullness (FF) was divided into six levels by visual observation of morphology ${ }^{49}$ where 0 is an empty intestine, 1 is $1 / 4$ full intestines, 2 is $1 / 2$ full intestines, 3 is $3 / 4$ full intestines, 4 is full intestines, and 5 is intestinal distension. 
The FF was a response variable, and size group and sampling times were fixed effects. A mixed linear model was fitted to analyze the effects of body size and sampling time on feeding activity. Time- and group-level predictors were included in the model (full model: FF $\sim$ Group + Time + Group $\times$ Time + (1|Season)), and new models were produced by reducing fixed effects step by step. To test the significance of fixed effects, the full model and other models were compared using ANOVA. Mixed linear models were fitted by the "lme4" package ${ }^{50}$. All statistical analyses were performed using R 3.6.1 ${ }^{51}$.

Trophic niche widths. Foregut contents were identified, and sorted into taxonomic groups down to the order level if possible. Prey importance was expressed by relative numerical abundance $(\% \mathrm{~N})$, and relative mass abundance $(\% \mathrm{~W})$. Mean proportional contribution of potential prey sources to black amur bream based on stable isotope ratios was calculated using the Stable Isotope Analysis in R (siar) package ${ }^{52}$. The black amur bream consumed mixtures of plant and animal material, thus the trophic enrichment factor (TEF) was assigned as $1.3 \pm 0.3 \%$, and $2.3 \pm 0.18 \%$ o for $\delta^{13} \mathrm{C}$ and $\delta^{15} \mathrm{~N}$, respectively ${ }^{53}$.

The mean distance to centroid (CD) measured the Euclidean distance of each sample to the mean $\delta^{13} \mathrm{C}$ and $\delta^{15} \mathrm{~N}$ values, to indicate average degree of trophic diversity. The CD can be partitioned into trophic level diversity $\left(\delta^{15} \mathrm{~N}\right.$ range: $\left.\mathrm{NR}\right)$, and carbon matter source diversity $\left(\delta^{13} \mathrm{C}\right.$ range: $\left.\mathrm{CR}\right)$. The isotopic niche width was based on the convex hull area (TA) that was calculated by the smallest convex polygon bounding the individuals in $\delta^{13} \mathrm{C}$ and $\delta^{15} \mathrm{~N}$ niche space ${ }^{54}$. The TA directly measured population niche width, reflecting variation in niche dimensions along two isotopes, is widely used to describe the isotopic niche width of fish ${ }^{55}$. The standard elliptical area (SEA) also represents dietary niche partitioning for each group, and contains $40 \%$ of studied individuals of a population without being affected by outliers ${ }^{56}$. The $\mathrm{SEA}_{c}$ was corrected by sample size in a bivariate distribution, being unbiased with respect to sample size ${ }^{54}$. The mean nearest neighbor distance (MNND) measured the trophic similarity between individuals through Euclidean distances in the biplot space ${ }^{54}$.

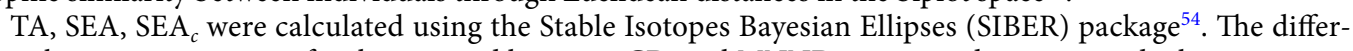
ences between size groups for the centroid location, CD, and MNND were tested using a residual permutation procedure (RPP) and the parametric Hotelling's $T^{2}$ test $^{57}$.

Niche overlap. Dietary overlap was calculated using the simplified Morisita's index ${ }^{58,59}$ :

$$
C_{i j}=2\left(\sum p_{i k} \cdot p_{j k}\right)\left(\sum p_{i k}^{2}+\sum p_{j k}^{2}\right)^{-1}
$$

where $C_{\mathrm{ij}}$, dietary overlap index for predators $i$ and $j p_{\mathrm{ik}}$ and $p_{\mathrm{jk}}$, biomass proportions of predators $i$ and $j$ with prey $k$ in their foregut. A $C_{\mathrm{ij}}$ value over 0.6 is considered a significant overlap.

Isotopic niche overlap was assessed by the extent of the overlapping area between the $\mathrm{SEA}_{\mathrm{c}}$ of two groups, which was measured by the percentage of overlapping $\mathrm{SEA}_{c}$ and compared between size groups ${ }^{60}$.

Individual specialization. The total niche width (TNW) of a population is the variance of total resource use of all individuals, can be divided into two components: the variation within individuals (WIC), and the variance between individuals $(\mathrm{BIC})^{61}$. The relative degree of individual specialization can be assessed by the proportion of TNW explained by WIC, WIC/TNW, and ranges from 0 to 1 . Smaller values of WIC/TNW indicate a lower individual overlap, and higher individual specialization ${ }^{62}$. The TNW and WIC of each group was expressed as follows ${ }^{62,63}$ :

$$
\begin{gathered}
\mathrm{TNW}=-\sum_{\mathrm{k}} \mathrm{q}_{\mathrm{k}} \ln \left(\mathrm{q}_{\mathrm{k}}\right) \\
\mathrm{WIC}=\sum_{\mathrm{i}} \mathrm{p}_{\mathrm{i}}\left(-\sum_{\mathrm{k}} \mathrm{p}_{\mathrm{ik}} \ln \left(\mathrm{p}_{\mathrm{ik}}\right)\right)
\end{gathered}
$$

where $p_{i}$ is the proportional numerical abundance of all resources used by individual $i$; $q_{k}$ is the proportion of the $k$ th resource category in a group's niche, and $p_{i k}$ is the proportion of resource $k$ used by individual $i$. Diet similarity calculates the mean pairwise diet similarity between all individuals in a group. The TNW, WIC/TNW, and diet similarity were calculated for each group by $\mathrm{RInSp}^{64}$.

Ethics statement. All experiments were performed under the approval of the Ethics Committee of Pearl River Fisheries Research Institute, Chinese Academy of Fishery Sciences. All methods were performed in accordance with the Chinese Association for the Laboratory Animal Sciences and the Institutional Animal Care and Use Committee (IACUC) protocols.

Received: 18 June 2020; Accepted: 1 October 2020

Published online: 21 October 2020

\section{References}

1. Jones, G. P. Competitive interactions among adults and juveniles in a coral reef fish. Ecology 68, 1534-1547 (1987).

2. Smith, C. L. Coral reef fish communities: A compromise view. Environ. Biol. Fish. 3, 109-128 (1978).

3. Belovsky, G. E. \& Jordan, P. A. The time-energy budget of a moose. Theor. Popul. Biol. 14, 76-104 (1978).

4. Ward, A. J. W., Webster, M. M. \& Hart, P. J. B. Intraspecific food competition in fishes. Fish Fish. 7, 231-261 (2006). 
5. Del Arco, A. I., Parra, G., Rico, A. \& Van den Brink, P. J. Effects of intra- and interspecific competition on the sensitivity of aquatic macroinvertebrates to carbendazim. Ecotoxicol. Environ. Saf. 120, 27-34 (2015).

6. Schoener, T. W. Resource partitioning in ecological communities. Science 185, 27-39 (1974).

7. Quintana, X. D. et al. Predation and competition effects on the size diversity of aquatic communities. Aquat. Sci. 77, 45-57 (2015).

8. Swanson, B. O., Gibb, A. C., Marks, J. C. \& Hendrickson, D. A. Trophic polymorphism and behavioral differences decrease intraspecific competition in a cichlid, Herichthys minckleyi. Ecology 84, 1441-1446 (2003).

9. Sánchez-Vázquez, F. J., Madrid, J. A., Zamora, S. \& Tabata, M. Feeding entrainment of locomotor activity rhythms in the goldfish is mediated by a feeding-entrainable circadian oscillator. J. Comp. Physiol. 181, 121-132 (1997).

10. Bolnick, D. I. et al. The ecology of individuals: Incidence and implications of individual specialisation. Am. Nat. 161, 1-28 (2003).

11. Araujo, M. S., Bolnick, D. I. \& Layman, C. A. The ecological causes of individual specialisation. Ecol. Lett. 14, 948-958 (2011).

12. Vindenes, Y., Engen, S. \& Saether, B. Individual heterogeneity in vital parameters and demographic stochasticity. Am. Nat. 171, $455-467$ (2008).

13. Duffy, M. A. Ecological consequences of intraspecific variation in lake Daphnia. Freshw. Biol. 55, 995-1004 (2010).

14. Schreiber, S. J., Bürger, R. \& Bolnick, D. I. The community effects of phenotypic and genetic variation within a predator population. Ecology 92, 1582-1593 (2011).

15. Darimont, C. T., Paquet, P. C. \& Reimchen, T. E. Stable isotopic niche predicts fitness of prey in a wolf-deer system. Biol. J. Linn. Soc. 90, 125-137 (2007).

16. Johnson, C. K. et al. Prey choice and habitat use drive sea otter pathogen exposure in a resource-limited coastal system. PNAS 106, 2242-2247 (2009).

17. Wagner, C. E., McIntyre, P. B., Buels, K. S., Gilbert, D. M. \& Michel, E. Diet predicts intestine length in Lake Tanganyika’s cichlid fishes. Funct. Ecol. 23, 1122-1131 (2009).

18. Pyke, G. H., Pulliam, H. R. \& Charnov, E. L. Optimal foraging: A selective review of theory and tests. Q. Rev. Biol. 52, 137-154 (1977).

19. MacArthur, R. H. \& Pianka, E. R. On optimal use of a patchy environment. Am. Nat. 100, 603-609 (1966).

20. Ackermann, M. \& Doebeli, M. Evolution of niche width and adaptive diversification. Evolution 58, 2599-2612 (2004).

21. Fausch, K. D. Profitable stream positions for salmonids: Relating specific growth rate to net energy gain. Revue Canadienne De Zoologie. 62, 441-451 (1984).

22. Metcalfe, N. B. Intraspecific variation in competitive ability and food intake in salmonids: Consequences for energy budgets and growth rates. J. Fish Biol. 28, 525-531 (1986).

23. Sol, D. et al. Ecological mechanisms of a resource polymorphism in Zenaida Doves of Barbados. Ecology 86, 2397-2407 (2005).

24. Lu, K. Fisheries Resources in Pearl River (ed. Lu, K.) 146-150 (Guangdong Science and Technology Press, 1990).

25. Xia, Y. et al. Small-subunit ribosomal DNA sequencing analysis of dietary shifts during gonad maturation in wild black Amur bream (Megalobrama terminalis) in the lower reaches of the Pearl River. Fish. Sci. 83, 955-965 (2017).

26. Li, J. et al. Species diversity of fish community of Provincial Xijiang River rare fishes natural reserve in Zhaoqing City, Guangdong Province. J. Lake Sci. 21, 556-562 (2009).

27. Zhang, Y. et al. Fish community structure and environmental effects of West River. South China Fish. Sci. 16, 42-52 (2020).

28. Li, Y. et al. Exploitation status of Megalobrama terminalis based on analysis of SBR and YPR models in Xijiang River. Acta Hydrobiol. Sin. 42, 975-983 (2018).

29. Svanbäck, R. \& Eklov, P. Effects of habitat and food resources on morphology and ontogenetic growth trajectories in perch. Oeco$\operatorname{logia} 131,61-70(2002)$.

30. Uchikawa, K. \& Kidokoro, H. Feeding habits of juvenile Japanese common squid Todarodes pacificus: Relationship between dietary shift and allometric growth. Fish. Res. 152, 29-36 (2014).

31. Carreonmartinez, L. B. \& Heath, D. D. Revolution in food web analysis and trophic ecology: Diet analysis by DNA and stable isotope analysis. Mol. Ecol. 19, 25-27 (2010).

32. Hardy, C. M., Krull, E. S., Hartley, D. M. \& Oliver, R. L. Carbon source accounting for fish using combined DNA and stable isotope analyses in a regulated lowland river weir pool. Mol. Ecol. 19, 197-212 (2010).

33. Peterson, B. J., Howarth, R. W. \& Garritt, R. H. Sulfur and carbon isotopes as tracers of salt-marsh organic matter flow. Ecology 67, 865-874 (1986).

34. Peterson, B. J., Howarth, R. W. \& Garritt, R. H. Multiple stable isotopes used to trace the flow of organic matter in estuarine food webs. Science 227, 1361-1363 (1985).

35. Peterson, B. J. \& Fry, B. Stable isotope in ecosystem studies. Annu. Rev. Ecol. Syst. 18, 293-320 (1987).

36. Post, D. M. Using stable isotopes to estimate trophic position: Models, methods, and assumptions. Ecology 83, 703-718 (2002).

37. Valen, L. V. Morphological variation and width of ecological niche. Am. Nat. 99, 377-390 (1965).

38. Lesser, J. S., James, W. R., Stallings, C. D., Wilson, R. M. \& Nelson, J. A. Trophic niche size and overlap decreases with increasing ecosystem productivity. Oikos https://doi.org/10.1111/oik.07026 (2020).

39. Pool, T. et al. Seasonal increases in fish trophic niche plasticity within a flood-pulse river ecosystem (Tonle Sap Lake, Cambodia). Ecosphere. 8, e01881 (2017).

40. Persson, L. Food consumption and the significance of detritus and algae to intraspecific competition in roach Rutilus rutilus in a shallow eutrophic lake. Oikos 41, 118-125 (1983).

41. Zhang, B. et al. Characteristics of aquatic vascular plant communities in Dongguan reaches of dongjiang river during two periods. Wetland Sci. 13, 284-290 (2015).

42. Bing, X. et al. Spatial and temporal difference of primary productivity and its influencing factors in the Pearl River Delta. South China Fish. Sci. 13, 1-8 (2017).

43. Slatkin, M. Ecological character displacement. Ecology 61, 163-177 (1980).

44. Steiner, C. F., Caceres, C. E. \& Smith, S. D. P. Resurrecting the ghost of competition past with dormant zooplankton eggs. Am. Nat. 169, 416-422 (2007).

45. Hamrin, S. F. \& Persson, L. Asymmetrical competition between age classes as a factor causing population oscillations in an obligate planktivorous fish species. Oikos 47, 223-232 (1986).

46. Taylor, R. C., Trexler, J. C. \& Loftus, W. F. Separating the effects of intra- and interspecific age-structured interactions in an experimental fish assemblage. Oecologia 127, 143-152 (2001).

47. Pan, B. Z., Wang, H. Z., Pusch, M. T. \& Wang, H. J. Macroinvertebrate responses to regime shifts caused by eutrophication in subtropical shallow lakes. Freshw. Sci. 34, 942-952 (2015).

48. Ru, H., Li, Y., Sheng, Q., Zhong, L. \& Ni, Z. River damming affects energy flow and food web structure: A case study from a subtropical large river. Hydrobiologia 847, 679-695 (2020).

49. Yin, M. 1995. The Fish Ecology (ed. Yin, M.) 266-267 (China Agriculture Press, Beijing, 1995).

50. Bates, D. M. lme4: Mixed-effects modeling with R. https://cran.r-project.org/web/packages/lme4/vignettes/lmer.pdf (2010).

51. R Core Team. R: a language and environment for statistical computing. https://www.R-project.org (2019).

52. Parnell, A. C., Inger, R., Bearhop, S., Jackson, A. L. \& Rands, S. Source partitioning using stable isotopes: Coping with too much variation. PLOS ONE 5, e9672 (2010).

53. McCutchan, J. H., Lewis, W. M., Kendall, C. \& Mcgrath, C. C. Variation in trophic shift for stable isotope ratios of carbon, nitrogen, and sulfur. Oikos 102, 378-390 (2003). 
54. Jackson, A. L., Inger, R., Parnell, A. C. \& Bearhop, S. Comparing isotopic niche widths among and within communities: SIBERStable Isotope Bayesian Ellipses in R. J. Anim. Ecol. 80, 595-602 (2011).

55. Layman, C. A., Quattrochi, J. P., Peyer, C. M. \& Allgeier, J. E. Niche width collapse in a resilient top predator following ecosystem fragmentation. Ecol. Lett. 10, 937-944 (2007).

56. Newsome, S. D., Martinez del Rio, C., Bearhop, S. \& Phillips, D. L. A niche for isotope ecology. Front. Ecol. Environ. 5, 429-436 (2007).

57. Turner, T. F., Collyer, M. L. \& Krabbenhoft, T. J. A general hypothesis-testing framework for stable isotope ratios in ecological studies. Ecology 91, 2227-2233 (2010).

58. Krebs, C. J. Ecological Methodology (ed. Krebs, C. J.) 466-496 (Harper and Row, Manhattan, 1989).

59. Hall, D. H., Raffaelli, D., Basfors, D. J., Robertson, M. R. \& Fryer, R. The feeding relationships of the larger fish species in a Scottish sea loch. J. Fish Biol. 37, 775-791 (1990).

60. Pinzone, M., Damseaux, F., Michel, L. N. \& Das, K. Stable isotope ratios of carbon, nitrogen and sulphur and mercury concentrations as descriptors of trophic ecology and contamination sources of Mediterranean whales. Chemosphere 237, 124448 (2019).

61. Roughgarden, J. Evolution of niche width. Am. Nat. 106, 683-718 (1972).

62. Bolnick, D. I., Yang, L. H., Fordyce, J. A., Davis, J. M. \& Svanbäck, R. Measuring individual-level resource specialization. Ecology 83, 2936-2941 (2002).

63. Roughgarden, J. Theory of Population Genetics and Evolutionary Ecology: An Introduction (ed. Roughgarden, J.) 510 (Macmillan, New York, 1979).

64. Zaccarelli, N., Bolnick, D. I. \& Mancinelli, G. RInSp: An r package for the analysis of individual specialization in resource use. Methods Ecol. Evol. 4, 1018-1023 (2013).

\section{Acknowledgements}

Special thanks are given to Dr. Yanyi Zeng for classifying the riparian plants. This work was supported by the Guangdong Basic and Applied Basic Research Foundation (2019B1515120064), National Natural Science Foundation of China (31602166), and Pearl River Fishery Resources Survey and Evaluation Innovation Team Project (2020TD10, 2020ZJTD-04).

\section{Author contributions}

Y.X. wrote the manuscript and did the data analysis. Y.L. collected the fish and plant samples. S.Z. collected the benthic animal samples. J.L. assist in intestinal content identification. S.L. prepared the samples for isotope analysis. X.L. designed the experiment.

\section{Competing interests}

The authors declare no competing interests.

\section{Additional information}

Correspondence and requests for materials should be addressed to X.L.

Reprints and permissions information is available at www.nature.com/reprints.

Publisher's note Springer Nature remains neutral with regard to jurisdictional claims in published maps and institutional affiliations.

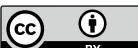

Open Access This article is licensed under a Creative Commons Attribution 4.0 International License, which permits use, sharing, adaptation, distribution and reproduction in any medium or format, as long as you give appropriate credit to the original author(s) and the source, provide a link to the Creative Commons licence, and indicate if changes were made. The images or other third party material in this article are included in the article's Creative Commons licence, unless indicated otherwise in a credit line to the material. If material is not included in the article's Creative Commons licence and your intended use is not permitted by statutory regulation or exceeds the permitted use, you will need to obtain permission directly from the copyright holder. To view a copy of this licence, visit http://creativecommons.org/licenses/by/4.0/.

(C) The Author(s) 2020 